\title{
Hypoinsulinemic Effects of Prunus Armeniaca Extract
}

\author{
Cherryhan Salvedia* \\ Physiology department, Misr International University, Egypt
}

Submission: June 04, 2017; Published: September 14, 2017

*Corresponding author: Cherryhan Salvedia, Physiology department, Misr International University, Research Center and Histopathology Laboratory, Misr International University, Cairo, Egypt. Tel: (+20) 1004107077; Email: han.salvedia@gmail.com

\begin{abstract}
Prunus armeniaca is rich in antioxidants with sucrose being the dominant sugar. Fructose consumption as a free Monosaccharide or high fructose diets could have a role in several adverse health consequences as insulin resistance, dyslipidemia, hyperuricemia, hypertension and weight gain. For long, hyperuricemia was considered a mere indicator of associating cardiovascular comorbidities. Recent studies demolished this association and comorbidities were attributed to recognized cardiovascular risk factors. Prunus armeniaca fruit extract improved periodontal inflammation and attenuated serum Nitric oxide, serum insulin and serum glucose levels of fructose fed rats.
\end{abstract}

Keywords: Prunus armeniaca fruit; Attenuated insulin levels; Hypouricemia; Hypoinsulinemia

Abbreviations: SBP: Systolic Blood Pressure; NO: Nitric Oxide; UA: Uric Acid; TG: Triglycerides

\section{Introduction}

In this current study, 36 male albino rats were allocated into 3 groups; a control group which received regular diet, untreated group which received both regular diet and fructose, while the treated group received regular diet, fructose and Prunus armeniaca fruit extract over a period of 10 weeks. Fructose; unlike glucose does not stimulate insulin release, thus cannot enter most cells [1] However, high concentrations of fructose (10-30mM) stimulates insulin secretion [2].

In liver, fructose is converted to lactate which stimulates de novo lipogenesis and inhibits lipolysis. Minor metabolic pathways include conversion of fructose to fatty acids by potent stimulation of de novo lipogenesis and fatty acids will be released into the circulation with VLDL [3]. Fructose cleavage by passes the regulatory feedback steps occurring in glucose metabolic pathways, thus Fructose is less regulated which contributes to the increase in fatty acid synthesis and obesity [4]. At the end of the study, both control and untreated groups showed statistically significant lowest mean serum TG levels ( $\mathrm{P} \leq 0.05) ; 81 \pm 2.7$ and $91.5 \pm 4.4$, with no significant difference between them, while the treated group showed statistically significant highest mean serum TG levels ( $\mathrm{P} \leq$ $0.05) ; 132.3 \pm 19$. 3 . Also mean body weights revealed statistical difference between the 3 groups ( $\mathrm{P} \leq 0.05)$, the treated group was significantly the lowest ( $\mathrm{P} \leq 0.05)$, while the control group was significantly the highest $(\mathrm{P} \leq 0.05)$. These findings support a recent report delivered by welsh et al concluding that obesity was a matter of balanced energy [4] independent of fructose rich diet. Fructose also produced proinflammatory cytokines in significant amounts leading to a rise in NO production [5].

Fructose phosphorylation can also contribute to the UA metabolism as liver uses NO to metabolize fructose and produce UA [1]. This could explain the statistically significant highest mean serum UA levels ( $\mathrm{P} \leq 0.05$ ); $4.5 \pm 0.4$ seen with the untreated group, while the control and treated groups showed the statistically significant lowest mean serum UA levels ( $P$ $\leq 0.05) ; 2.2 \pm 0.2$ and $2.3 \pm 0.5$ respectively with no statistical significant difference between them.

Since excess serum UA is often also seen in metabolic syndrome [6] it was suggested to play a role in blood pressure, diabetes, cardiovascular diseases [7]. It acts as an antioxidant when administered to improve vascular endothelial function in patients with type I diabetes and smokers [8]. However, in rats fed fructose rich diet, hypertension occur secondary to hyperuricemia and hyperinsulinism [9]. The absence of a 
statistical significant difference in mean SBP between the 3 groups contradicts with the fact that serum UA levels could be a reflection for cardiovascular diseases. This supports the significant high mean serum NO levels observed with the untreated group $44.4 \pm 3.3$, while the mean serum NO levels of the treated group were attenuated to $21 \pm 2.9$ when compared to the control group $13.9 \pm 1.1$ suggesting a possible role played by the NO in preventing significant elevation of SBP.

$60-70 \%$ of UA is excreted by the kidney [10] while $30-40 \%$ in the intestine [6] Normally, It was found that UA clearance is inversely related to insulin resistance [11] However, Physiological hyperinsulinemia does not affect Serum UA levels [12]. This is supported by findings in this study as the untreated group showed the statistically significant $(\mathrm{P} \leq 0.05)$ highest mean serum Insulin; $10.9 \pm 1$, the control group showed the lowest statistically significant $(P \leq 0.05)$ mean serum Insulin; $3.7 \pm 0.3$, while the treated group showed statistically significant $(P \leq 0.05)$ attenuated mean serum Insulin; $6.4 \pm 1.2$. Similarly, mean serum glucose was attenuated in treated group, but statistically lowest in the control group ( $\mathrm{P} \leq 0.05)$ Some studies also suggested possible detrimental effects of hyperuricemia on the kidneys [9] and urateactivates the immune system [8].

The periodontal tissues in the untreated group revealed mild inflammation, but was absent in the periodontal tissues of the control and the treated groups. These findings support UA as an injurious factor to cells and support the antioxidant role or the lowering effect played by the fruit extract on the serum UA levels. However, the absent histopathological changes in the renal tissues of all groups in association with a significantly high serum creatinine levels in the untreated group and attenuated levels in the treated group suggest that chronic effects or higher levels of Serum UA are required to induce detrimental changes in the renal tissues.

\section{Conclusion}

The elevated Serum UA, insulin and glucose levels in the untreated group and its attenuated levels seen with the treated group suggests that UA has an important role in the pathogenesis of insulin resistance and diabetes, while the absence of associating obesity and hypertension excludes UA as an indicator of cardiovascular risk factors and suggests alternative or even multi factorial theories for obesity. The significantly high mean serum TG levels in the treated group require further investigation. The attenuated serum NO levels seen in the treated group also suggest that the fruit extract elicited its potential antioxidants effects through a mechanism different than Nitric oxide synthase.

\section{References}

1. George AB (2007) How bad is fructose? Am J Clin Nutr 86(4): 895-896.

2. Laughlin MR (2014) Normal roles for dietary fructose in carbohydrate metabolism. Nutrients 6(8): 3117-3129.

3. Luc T, Lê KA (2010) Metabolic Effects of Fructose and the Worldwide Increase in Obesity. Physiol Rev 90(1): 23-46.

4. Sam ZS, Mark WE (2012) Fructose metabolism in humans. Nutr Metab (Lond) 9(1): 89

5. Samraa HAK, Kamel MA, Hassanin, Khalid S, Hashem (2016) The effect of high dietary fructose on the kidney of adult albino rats and the role of curcumin supplementation: A biochemical and histological study. Beni-Suef University Journal of Basic and Applied Sciences 5(1): 52-60.

6. Brian JDB, Oliver K, Hideji F, Annette S, Kelle M (2014) Early-onset metabolic syndrome in mice lacking the intestinal uric acid transporter SLC2A9. Nat Commun 5: 4642.

7. Mark JC, Patricia BM, Deb ON, Kate W, Fadi JC, et al. (2008) SLC2A9 is a high-capacity urate transporter in humans. PLoS Med 5(10):e197.

8. Michael SL (2012) Regulation of Uric Acid Excretion by the Kidney. Curr Rheumatol Rep 14(2): 179-188.

9. Fernando PR, Nicola D, Tomas B (2015) A Review of Uric Acid, Crystal Deposition Disease, and Gout. Adv Ther 32: 31-41.

10. Akifumi K, Kentaro T, Shigeko H, Shoji K (2014) Linking uric acid metabolism to diabetic complications. WJD 5(6): 787-795.

11. Francesco F, Ida CYD, Clarie BH, Gerald MR (1991) Relationship between resistance to insulin-mediated glucose uptake, urinary uric acid clearance, and plasma uric acid concentration. JAMA 266(21):3008-3011.

12. Quiñones GA, Natali A, Baldi S, Frascerra S, Sanna G, et al. (1995) Effect of insulin on uric acid excretion in humans. Am J Physiol 268(1): E1-5.

\section{Your next submission with Juniper Publishers will reach you the below assets}

- Quality Editorial service

- Swift Peer Review

- Reprints availability

- E-prints Service

- Manuscript Podcast for convenient understanding

- Global attainment for your research

- Manuscript accessibility in different formats ( Pdf, E-pub, Full Text, Audio)

- Unceasing customer service

Track the below URL for one-step submission https://juniperpublishers.com/online-submission.php 